\title{
Public Infrastructures, Public Consumption, and Welfare in a New-Open-Economy-Macro Model
}

Giovanni Ganelli and Juha Tervala 



\title{
IMF Working Paper
}

Fiscal Affairs Department

Public Infrastructures, Public Consumption, and Welfare in a New-Open-Economy-Macro Model Prepared by Giovanni Ganelli* and Juha Tervala*

Authorized for distribution by Manmohan S. Kumar

March 2007

\begin{abstract}
This Working Paper should not be reported as representing the views of the IMF. The views expressed in this Working Paper are those of the author(s) and do not necessarily represent those of the IMF or IMF policy. Working Papers describe research in progress by the author(s) and are published to elicit comments and to further debate.

This paper focuses on the trade-off faced by governments in deciding the allocation of public expenditures between productivity-enhancing public infrastructures and utility-enhancing public consumption. From the modeling point of view, the paper augments a standard New Open Economy Macroeconomics (NOEM) model by introducing productive public infrastructures. The results show that a temporary increase in the domestic stock of public capital financed by a reduction in public consumption reduces domestic welfare in the short run because the temporary gains from higher productivity do not compensate domestic residents for the utility loss due to lower public consumption. If the policy shift is permanent domestic utility is likely to increase, while foreign residents suffer short-run welfare losses but benefit from welfare gains in the long run. This analysis implies that a permanent domestic reallocation of public spending might result in a virtuous global technological cycle.

JEL Classification Numbers: E62, F41, H42, H54

Keywords: Public Spending Composition, Welfare, Imperfect Competition, Nominal Rigidities.

Authors’ E-Mail Addresses: gganelli@imf.org,juha.tervala@helsinki.fi

* Giovanni Ganelli is an Economist in the Fiscal Affairs Department of the IMF. Juha Tervala is a Researcher at the University of Helsinki. The authors are grateful for comments to Manmohan Kumar and Mark De Broeck.

Juha Tervala would like to thank the Yrjö Jahnsson foundation for financial support. The opinions presented are those of the authors and should not be attributed to the International Monetary Fund, its Executive Board, or its management.
\end{abstract}




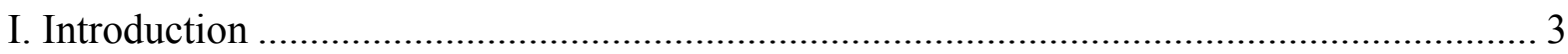

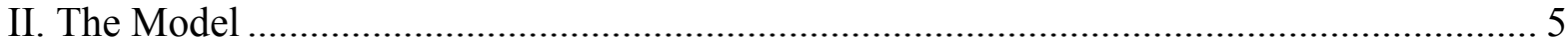

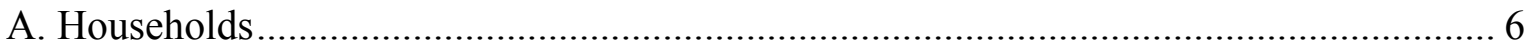

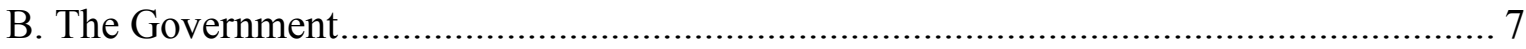

C. Private Firms .................................................................................................... 8

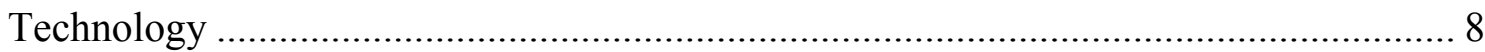

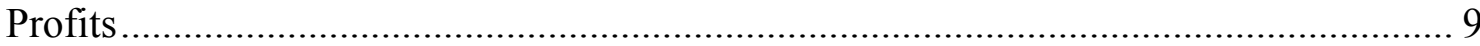

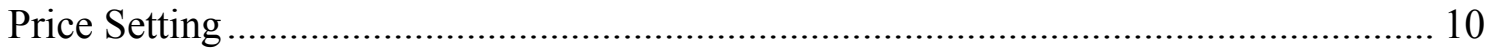

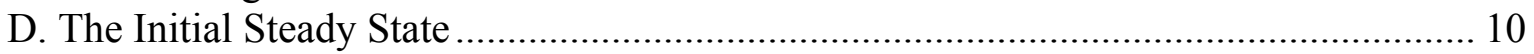

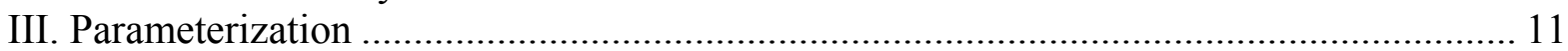

IV. A Permanent Shift in Government Spending Composition........................................ 12

A. The Impact on the Domestic Economy.................................................................... 12

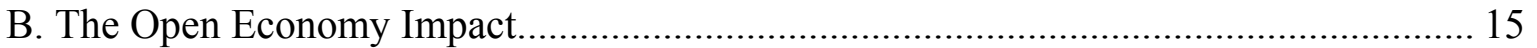

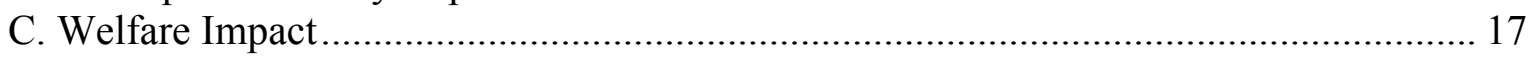

Domestic Welfare ............................................................................................ 17

Foreign Welfare ................................................................................................. 18

V. A Temporary Shift in Government Spending Composition ......................................... 19

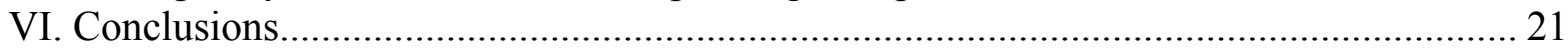

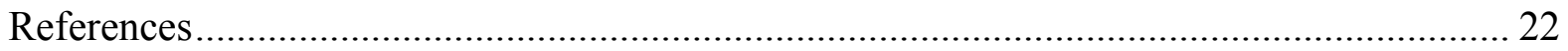

Figures

Figure 1. The Effects of a Permanent Shift in Government Spending Composition..............13

Figure 2. The Effects of a Temporary Shift in Government Spending Composition ..............20 


\section{INTRODUCTION}

Governments face several trade-offs in the process of planning and executing fiscal policy. For example, a decision on the appropriate fiscal stance needs to take in to account both the short-run impact on the economy and the long-run sustainability of public finances.

Furthermore, decisions on the methods of financing the deficit (or on the use of the surplus) and on the composition of public expenditures also need to be made.

With regard to the latter issue, governments are involved in the provision of public infrastructures which can increase the productivity of private firms. ${ }^{1}$ Examples include roads, bridges, airports, and all "... those public works, which, though they may be in the highest degree advantageous to a great society, are, however, of such a nature that the profit could never repay the expense to any individual or small number of individuals, and which it therefore cannot be expected that any individual or small number of individuals should erect or maintain." (Adam Smith 1776). At the same time, governments spend large part of their budgets on goods and services that can also be privately provided (such as education, health, and insurance programs) and are likely to directly impact consumers utility in a way similar to private consumption.

This trade-off between productivity-enhancing public investment and utility-enhancing public consumption is often at the forefront of the public debate and policy discussions, but has received less attention than it deserves in the academic literature. Several authors, particularly since the work of Aschauer (1989) have investigated, both theoretically and empirically, the consequences of productive public spending. This literature includes Baxter and King (1993), Glomm and Ravikumar (1993), Gramlich (1994), Rioja (1999, 2003), Feltenstein and Morris (1990), Kalaitzidakis and Kalyvitis (2004), Coto-Martinez (2006), Duggal, Saltzman and Klein (2007), Linnemann and Schabert (2006), and Tervala (2006). Very few papers in this literature, however, explicitly focus on the trade-off between productive infrastructure spending and the welfare effects of public consumption. Prominent exceptions are Barro (1990), who incorporates tax-financed government services that affect production and utility into an endogenous growth model, and Turnovsky and Fisher (1995), who carry out a similar analysis using a neoclassical intertemporal framework.

In this paper we analyze the trade-off related to government spending composition in the context of a New Keynesian two-country model with imperfect competition and nominal rigidities. Our model belongs to the so-called New Open Economy Macroeconomics (NOEM) framework, which many currently regard as the workhorse model for the analysis of macroeconomic issues in open economies. ${ }^{2}$

\footnotetext{
${ }^{1}$ Throughout the paper, we will use interchangeably the expressions infrastructure expenditure and capital expenditure. Public infrastructures and public capital will also be used as synonymous.

${ }^{2}$ The NOEM literature originated with the seminal paper of Obstfeld and Rogoff $(1995,1996)$. Subsequent important contributions include, but are not limited to, Betts and Devereux (2000, 2001), Corsetti and Pesenti (2001), Devereux and Engel (2002), Obstfeld and Rogoff (2000, 2002), Hau (2000), Tille (2001), Benigno and Benigno (2003), Bergin (2003), Kollman (2002), Sutherland (1996, 2005), Pierdzioch (2004), and Ghironi
} 
Compared to the existing literature, one important contribution of our paper is that of analyzing productive public infrastructure spending in this new modeling paradigm. While some of the papers that we reviewed contain ingredients of the New Keynesian open economy paradigm, we are not aware of any paper that analyses the implications of public capital in a model that features at the same time imperfect competition, nominal rigidities and a two-country world. ${ }^{3}$ Our setup allows us to analyze the interactions between public infrastructure spending and the main market distortions that are likely to affect policies in real economies. The open-economy dimension allows us to also study the impact of a shift in domestic government spending composition on the current account and the exchange rate, as well as on foreign variables.

In addition, as we already stressed above, the only papers of which we are aware that explicitly focus on the trade-off between productive government spending and utility from public consumption (Barro 1990; Turnovsky and Fisher 1995) do not belong to the New Keynesian strand of literature and do not consider market imperfections. The analysis of how the trade-off is affected by such imperfections is another important contribution of our paper.

More in general, we see our paper as furthering the theoretical analysis of fiscal policy. This is important because while policy makers in several countries are showing a renewed interest in the fiscal instrument and an increasing number of academic and policy studies are focusing on fiscal issues, the analysis of the macroeconomic and welfare impact of fiscal policy still receives limited attention compared with that of monetary policy. In addition, as stressed by Alesina and Perotti (1995), the academic debate on fiscal policy tends to neglect composition issues. Fiscal policy is therefore usually modeled with reference to a general aggregate, often identified exclusively in terms of government consumption of goods and services. ${ }^{4}$ This implies that additional work taking into account the complexity of fiscal policy and the multidimensionality of governments' fiscal activities can be particularly valuable. The spirit of this paper is that of contributing to foster the debate in this area.

Our analysis shows that a permanent increase in domestic public infrastructure financed by a reduction in public consumption is likely to be welfare enhancing for domestic residents, provided that the productivity of public capital is not too low and the weight of public consumption (compared to private consumption) in private utility not too high. However, since a negative net welfare impact cannot be ruled out, one policy implication is that governments should take into account household preferences with respect to public provision of goods and services in deciding the composition of public spending. Governments should

(2006). Surveys of this literature are provided by Lane (2001), Sarno (2001), and Lane and Ganelli (2003). Coutinho (2005) focuses on the fiscal NOEM literature.

${ }^{3}$ Tervala (2006) develops a NOEM model in which the flow of government spending, not the stock of public capital, is an input to private producers.

${ }^{4}$ Noteworthy exceptions, besides the papers already mentioned above, are Roche (1996), Finn (1998), and Lane and Perotti (2003). 
also carefully evaluate the impact of planned infrastructure projects on the productivity of the private sector before changing the public spending mix.

The implementation of such a policy, moreover, also has important international implications. In particular, the welfare spillover on foreign utility is likely to be negative in the short run, because foreign residents have to meet increased global demand within a relatively underdeveloped (compared to domestic) public infrastructure system. However, foreign residents can benefit from long-run welfare gains. One implication of this analysis is that the domestic policy change can generate incentives for reallocation of public spending also abroad, as the foreign country tries to avoid short-run welfare losses by also increasing the level of its productive public capital. A domestic policy shift can therefore result in a virtuous global technological cycle.

If the domestic shift in public spending composition is temporary, domestic welfare is likely to be reduced because the temporary gains from higher productivity do not fully compensate domestic residents for the utility loss due to lower public consumption. This implies that governments which value the welfare of their citizens should ensure, before embarking on large public infrastructure projects, that the fiscal resources necessary to maintain the increased capital stock can be secured in the medium and long run. If this is not the case, the temporary increase in domestic productivity might not be enough to compensate for the utility loss due to lower public consumption.

The rest of the paper is organized as follows. Section 2 introduces the model. Section 3 discussed the parameterization. Sections 4 and 5 present and discuss the results for the case of a permanent and of a temporary shift in public spending composition, respectively. Section 6 concludes.

\section{THE MODEL}

The model is a standard NOEM model, similar to that developed by Betts and Devereux (2000). Compared to the latter, there are three main differences. The first is the introduction of productive public capital. The second is the assumption that public consumption affects private utility. Finally, nominal rigidities take the form of staggered price setting as in Calvo (1983), rather than one-period fixed prices.

Betts and Devereux (2000) assume that a fraction of firms fix prices in the currency of the consumer. Their model therefore allows for both Local Currency Pricing (LCP) - which implies deviations from Purchasing Price Parity (PPP) - and Producer Currency Pricing (PCP). In this paper we will restrict our attention to the PCP case, in order to focus on the international impact of government spending composition, rather than on deviations from PPP. The model contains two countries. Firms and households are indexed by $z \in[0,1]$. A fraction $n$ of households and firms are located in the domestic country, while $1-n$ are located in the foreign country. ${ }^{5}$

\footnotetext{
${ }^{5}$ In the description of the model that follows, unless equations for the foreign country are explicitly discussed they can be assumed to be symmetric to the equations for the domestic country.
} 


\section{A. Households}

Domestic households gain utility from private and public consumption and real balances. They also experience disutility from supplying labor. The domestic utility function is therefore given by

$U_{t}=\sum_{s=t}^{\infty} \beta^{s-t}\left[\log C_{s}+\frac{\chi}{1-\varepsilon}\left(\frac{M_{s}}{P_{s}}\right)^{1-\varepsilon}-\frac{l_{s}(z)^{2}}{2}+\phi \log G_{t}^{C}\right]$

where $0<\beta<1$ is the discount factor, $C$ is a composite good representing private consumption and $P_{s}$ is the price index associated with it. $G_{s}{ }^{C}$ represents public consumption. $M_{s}$ denotes nominal money balances and $l_{s}(z)$ the household's supply of labor; $\varepsilon>0$ is the inverse of the consumption elasticity of money demand, and $\chi$ and $\phi$ are positive parameters.

The composite private consumption good is defined in the following equation as an aggregate across the individual goods produced by firms

$$
C_{t}=\left[\int_{0}^{1} c_{t}(z)^{\frac{\theta-1}{\theta}} d z\right]^{\frac{\theta}{\theta-1}}
$$

where $\theta$ is the elasticity of substitution between any pair of individual goods. The associated price index is

$$
P_{t}=\left[\int_{0}^{n} p_{t}(z)^{1-\theta} d z+\int_{n}^{1}\left(E_{t} p_{t}^{*}(z)\right)^{1-\theta} d z\right]^{\frac{1}{1-\theta}}
$$

Where $p_{t}(z)$ is the price of good $z$ expressed in domestic currency, $p_{t}^{*}(z)$ is the foreign currency price of foreign good $\mathrm{z}$ and $\mathrm{E}$ is the exchange rate, defined as the price of the foreign currency in terms of the domestic currency.

The budget constraint of the domestic representative household is given by

$$
M_{t}+\delta_{t} D_{t}=D_{t-1}+M_{t-1}+w_{t} l_{t}(z)-P_{t} C_{t}+\pi_{t}-P_{t} \tau_{t}
$$

where $D$ denotes household's holding of domestic currency denominated nominal bonds, which account for international shifts in wealth, $\delta$ is the price of a bond (the inverse of one plus the nominal interest rate), $w_{t}$ is the nominal wage paid to the household in a competitive labor market, $\pi$ is the household's share of profits received by firms and $\tau$ denotes real lumpsum taxes paid to the government. 
Given that bonds are denominated in domestic currency, the budget constraint of the foreign representative household is

$M_{t}^{*}+\delta_{t}^{*} \frac{D_{t}^{*}}{E_{t}}=\frac{D_{t-1}^{*}}{E_{t}}+M_{t-1}^{*}+w_{t}^{*} l_{t}^{*}(z)-P_{t}^{*} C_{t}^{*}+\pi_{t}^{*}-P_{t}^{*} \tau_{t}^{*}$

where foreign variables are denoted by asterisks.

The first order conditions are given by

$$
\begin{aligned}
& \delta_{t} P_{t+1} C_{t+1}=\beta P_{t} C_{t} \\
& \delta_{t}^{*} P_{t+1}^{*} C_{t+1}^{*} E_{t+1}=\beta P_{t}^{*} C_{t}^{*} E_{t} \\
& l_{t}=\frac{w_{t}}{C_{t} P_{t}} \\
& l_{t}^{*}=\frac{w_{t}^{*}}{C_{t}^{*} P_{t}^{*}} \\
& \frac{M_{t}}{P_{t}}=\left(\frac{\chi C_{t}}{1-\delta_{t}}\right)^{\frac{1}{\varepsilon}} \\
& \frac{M_{t}^{*}}{P_{t}^{*}}=\left(\frac{\chi C_{t}^{*}}{1-\frac{\delta_{t}^{*} E_{t+1}}{E_{t}}}\right)^{\frac{1}{\varepsilon}}
\end{aligned}
$$

Equations (6) and (7) are the Euler equations for optimal domestic and foreign consumption, respectively. Equations (8) and (9) are the domestic and foreign optimal labor supply equations, which equate the disutility of supplying an extra unit of labor with the marginal utility of the extra private consumption that can be bought due to the marginal increase in labor supply. Finally, equations (10) and (11) show that households' optimal money demand is an increasing function of private consumption and a decreasing function of the interest rate.

\section{B. The Government}

The government budget constraint, expressed in per-capita terms, is given by

$$
G_{t}=\tau_{t}+\frac{M_{t}-M_{t-1}}{P_{t}}
$$

where total government spending $G_{t}$ is distributed between public consumption $G_{t}^{C}$ and public capital $G_{t}^{I}$, according to the formula $G_{t}=G_{t}^{C}+G_{t}^{I}$. 
Government consumption takes the same form as the private sector's consumption index and it is thus given by

$$
G_{t}^{C}=\left[\int_{0}^{1} g_{t}^{C}(z)^{\frac{\theta-1}{\theta}} d z\right]^{\frac{\theta}{\theta-1}}
$$

An analogous index governs public capital spending. Government spending on public capital and consumption are assumed to follow a first-order autoregressive process described by the following equations

$$
\begin{aligned}
& \hat{G}_{t}^{I}=\rho \hat{G}_{t^{-1}}^{I}+\sigma_{t}^{I} \\
& \hat{G}_{t}^{C}=\rho \hat{G}_{t-1}^{C}+\sigma_{t}^{C}
\end{aligned}
$$

where $\rho$ governs the persistence of a fiscal shock, $\sigma^{I}$ and $\sigma^{C}$ are unpredictable shifts in the components of government spending and the hat notation represents percentage deviations from the initial steady state.

\section{Private Firms}

\section{Technology}

Each firm produces a differentiated good. The production function of a representative domestic firm $\mathrm{z}$ is

$y_{t}(z)=l_{t}(z)\left(K_{0}+K_{t}^{G}\right)^{\alpha}$

where $y_{t}(z)$ is the output of firm $z$ and $l_{t}(z)$ is the labor input used by firm $z . K_{0}$ is the country's initial endowment of public capital — independent of government spending — which captures the impact of natural resources. $K^{G}$ is the stock of public capital provided by government spending, which evolves according to

$$
K_{t+1}^{G}=(1-\lambda) K_{t}^{G}+G_{t}^{I}
$$

where $\lambda$ is the depreciation rate.

One obvious shortcoming of our model is the assumption that private capital does not enter the production function of private firms. This is a limitation shared with large part of the NOEM literature, which usually assumes that labor is the only factor of production. The papers - discussed in the Introduction - which focus on the introduction of productive public spending in a closed economy usually assume that private capital also enters the production 
function. Since our framework complicates the modeling strategy by introducing the open economy dimensions, we abstract from private capital so as to avoid overly complicating the model. ${ }^{6}$

\section{Profits}

Domestic firms minimize their costs $w_{t} l_{t}(z)$ subject to (16). The nominal marginal cost is given by

$$
M C_{t}(z)=\frac{w_{t}}{\left(K_{0}+K_{t}^{G}\right)^{\alpha}}
$$

The profits of domestic firms are given by

$$
\pi_{t}(z)=p_{t}(z) y_{t}(z)-w_{t} l_{t}(z)
$$

Equations (19) and (12) can be substituted into the households' budget constraint equation (4) to derive the consolidated budget constraint of the domestic economy

$\delta_{t} D_{t}=D_{t-1}+p_{t}(z) y_{t}(z)-P_{t} C_{t}-P_{t} G_{t}$

Making use of the global asset-market-clearing condition $n D_{t}+(1-n) D_{t}^{*}=0$, the consolidated budget constraint of the foreign economy can be derived in an analogous way as

$$
-\frac{n}{1-n} \delta_{t}^{*} \frac{D_{t}}{E_{t}}=-\frac{n}{1-n} \frac{D_{t-1}}{E_{t}}+p_{t}^{*}(z) y_{t}^{*}(z)-P_{t}^{*} C_{t}^{*}-P_{t}^{*} G_{t}^{*}
$$

The fact that the law of one price holds in each country and domestic and foreign households consume identical consumption baskets implies the following demand curve for each differentiated good $z$

$y_{t}(z)=\left(\frac{p_{t}(z)}{P_{t}}\right)^{-\theta}\left(C_{t}^{W}+G_{t}^{W}\right)$

where $C_{t}^{W}$ is world private consumption demand, given by

$C_{t}^{W}=n C_{t}+(1-n) C_{t}^{*}$

\footnotetext{
${ }^{6}$ Introduction of private capital is left for future research. If public and private capital are complements in production, the results that we present are likely to be qualitatively similar to those in a model which also includes private capital.
} 
and world total government spending $G_{t}^{W}$ is defined in an analogous way.

\section{Price Setting}

In the absence of nominal rigidities, each home firm would maximize its profits using $p(z)$ as the choice variable. This would imply

$p_{t}(z)=\frac{\theta}{\theta-1} M C_{t}(z)$

Following Calvo (1983), we introduce nominal rigidities by assuming that each firm resets its prices with a probability $1-\gamma$ in each period, independently of other firms and independently of the time elapsed since the last adjustment. Each firm has to take into account, when setting its profit-maximizing price, that in every subsequent period there is a probability $0<\gamma<1$ that it will not be able to revise its price setting decision. When setting a new price in period $t$, each firm seeks to maximize the present value of profits weighting future profits by the probability that the price will still be effective in that period. Thus the representative home firm seeks to maximize

$$
\max _{p_{t}(z)} V_{t}(z)=\sum_{s=t}^{\infty} \gamma^{s-t} \zeta_{t, s} \pi_{s}(z)
$$

where $\zeta_{t, s}$ is the domestic discount factor between period $t$ and period $\mathrm{s}$, defined as $\zeta_{t, s}=\Pi_{j=s}^{t}\left(1+R_{j}\right)^{-1}$, where $\mathrm{R}$ is the domestic nominal interest rate. The result is that the pricing rule for home good $\mathrm{z}$ is given by

$p_{t}(z)=\left(\frac{\theta}{\theta-1}\right) \frac{\sum_{s=t}^{\infty} \gamma^{s-t} \zeta_{t, s}\left(C_{s}^{W}+G_{s}^{W}\right)\left(\frac{1}{P_{s}}\right)^{-\theta} M C_{s}(z)}{\sum_{s=t}^{\infty} \gamma^{s-t} \zeta_{t, s}\left(C_{s}^{W}+G_{s}^{W}\right)\left(\frac{1}{P_{s}}\right)^{-\theta}}$

All firms in a country are symmetric and every firm that changes its price in any given period chooses the same price and output consistently with (26). The structure of price setting implies that each period a fraction of $1-\gamma$ of firms sets a new price and the remaining fraction keeps their price unchanged.

\section{The Initial Steady State}

The model is log-linearized around a symmetric steady state where all exogenous variables are constant. In addition, we consider the special case where initial net foreign assets and government capital spending are both zero. While the assumption of zero initial capital 
spending is made more for tractability than for realism, it is not less realistic than the assumption usually made in existing NOEM models that total government spending is zero at the initial steady state. We depart from the latter by assuming that government consumption is positive and equal in both countries at the initial steady state. This will allow us to carry out policy exercises in which a reduction in public consumption is used to finance an increase in public capital. We also assume that the initial level of private consumption is equal in both countries.

Our assumptions imply that the optimal labor supply (8), the pricing rule (24), the production function (16) and their foreign equivalent equations can be combined to yield the following relationships between steady-state output, labor supply, and consumption

$y_{0}=\frac{\theta-1}{\theta} \frac{K_{0}^{2 \alpha}}{C_{0}}$

$l_{0}=\frac{\theta-1}{\theta} \frac{K_{0}^{\alpha}}{C_{0}}$

$y_{0}^{*}=\frac{\theta-1}{\theta} \frac{K_{0}^{* 2 \alpha}}{C_{0}^{*}}$

$l_{0}^{*}=\frac{\theta-1}{\theta} \frac{K_{0}^{* \alpha}}{C_{0}^{*}}$

where 0 subscripts denote the initial steady state. ${ }^{7}$

\section{Parameterization}

The parameterization of the model mostly follows Sutherland (1996). The elasticity of substitution between differentiated goods $\theta$ is set equal to 6 , implying a 20 percent mark-up of prices over marginal costs in the steady state. The subjective discount factor $\beta$ is set at $1 / 1.05$. The price stickiness parameter $\gamma$ is assumed to be equal to 0.5 , implying an average delay between price adjustments of two periods. The consumption elasticity of money demand parameter $\varepsilon$ is fixed at 9 . We normalize the endowment of natural resources in each country as follows: $K_{0}=K_{0}^{*}=1$. The two countries are assumed to be of equal size, i.e. $n=0.5$. The ratio of initial total government spending (i.e. initial public consumption to output) is set to 0.2 . This implies $G_{0}=G_{0}^{C}=G_{0}^{*}=G_{0}^{C^{*}}=0.204 ; C_{0}=C_{0}^{*}=0.816$; and $Y_{0}=Y_{0}^{*}=1.02$.

\footnotetext{
${ }^{7}$ The derivation of equations (27)-(30) is also based on the fact that initial output is equal to the sum of initial private and public consumption in each country. This is a consequence of the assumption of zero initial net foreign assets holdings.
} 
In the benchmark simulations presented below, we assume that the utility provided by public consumption is low compared to that provided by private consumption. We therefore set $\phi=0.4$. We also need to specify values for the productivity and depreciation rate of public capital parameters, $\alpha$ and $\lambda$. The depreciation rate of public capital $\lambda$ is assumed to be 0.10 (as in Baxter and King 1993 and Rioja 2003). The existing literature is far from conclusive on what a plausible value for $\alpha$ could be. Glomm and Ravikumar (1997) surveys paper which have attempted to estimate the productivity of public capital. Results vary from a statistically insignificant $\alpha$ (Hulten and Schwab 1991) to 0.39 (Aschauer 1989). Although Aschauer's upper bound is widely cited, most studies criticize it as too high and find estimates which are positive but much smaller. We therefore consider two values of $\alpha$ in our experiments, $\alpha=0.05$ (as in Baxter and King 1993) and $\alpha=0.1$ (as in Rioja 2003).

In what follows we consider the domestic and international impact of both permanent and temporary shocks to government spending composition in the domestic country. In the case of permanent shocks the persistency parameter $\rho$ is set to 1 in equations (14) and (15). In the case of temporary shocks, we set this parameter to 0.8 . We simulate the model using the algorithm developed by Klein (2000) and McCallum (2001).

\section{A Permanent Shift in Government Spending Composition}

In this section we consider a permanent one percentage increase in home government infrastructure investment relative to initial output and a simultaneous one percentage decrease in home government consumption relative to initial output. Total government spending is therefore constant both at home and in the foreign country. The composition of foreign public spending is unchanged compared to the initial steady state. We evaluate the impact of such a policy on the main domestic and foreign macroeconomic variables as well as on domestic and foreign momentary utility.

The results for this case are presented in Figure 1. The vertical axes show percentage deviations from the initial steady state. For variables whose initial steady state value is zero, the percentage deviations are expressed in relation to initial output.

\section{A. The Impact on the Domestic Economy}

Figure 1 shows that a shift in the composition of public spending towards public capital generates a boom in the domestic economy, by increasing domestic output. This is consistent with the findings of other papers which have investigated the impact of an increase in public capital in closed economies (for example, Baxter and King 1993). The basic intuition for this result is that an increase in public capital leads to an expansion of production possibilities, thus implying an increase in domestic output. Compared to a purely neoclassical framework the expansionary impact is likely to be augmented in our model by the fact that the initial output steady state is sub-optimally low due to the presence of imperfect competition.

Since the accumulation of public capital is gradual, the increase in domestic output is equally gradual, with an almost insignificant impact in the short run. However, since domestic households anticipate the medium and long-run increase in output, they increase private 
consumption immediately in order to smooth consumption intertemporally. This implies that the domestic economy must run a current account deficit in the short run to be able to consume more than it is producing in anticipation of future productivity gains. Consequently, in order to service the accumulated external debt domestic output has to increase more than consumption in the long run.

Figure 1. The Effects of a Permanent Shift in Government Spending Composition

(a) Domestic output

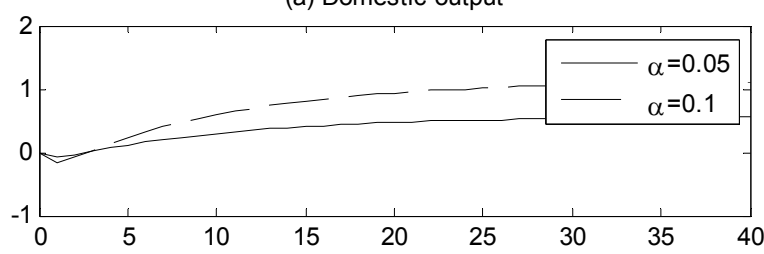

(c) Foreign output

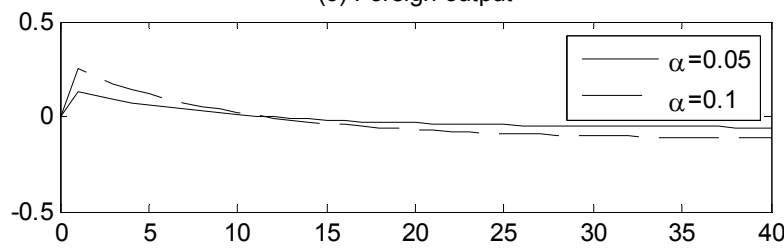

(e) Nominal exchange rate

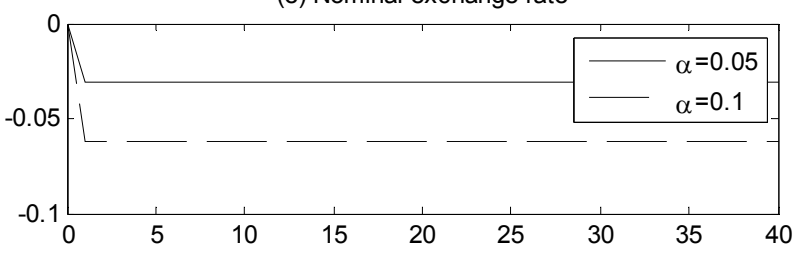

(g) Domestic public capital

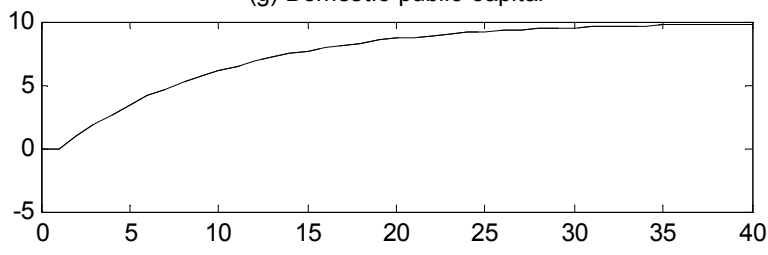

(i) Domestic welfare

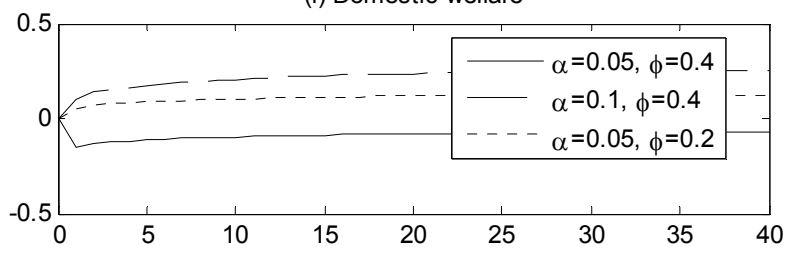

(b) Domestic private consumption

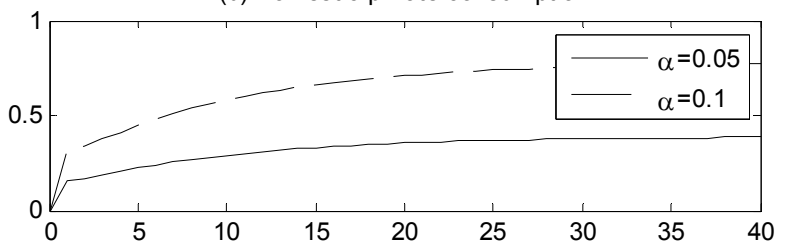

(d) Foreign private consumption

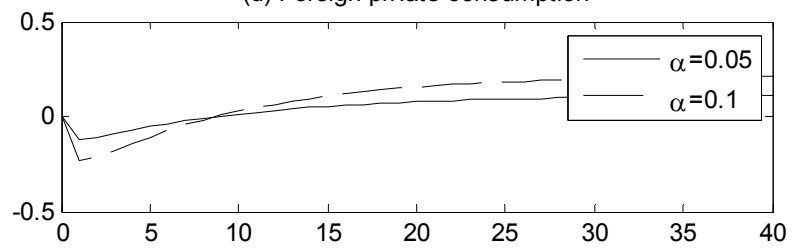

(f) Bond holdings of domestic households

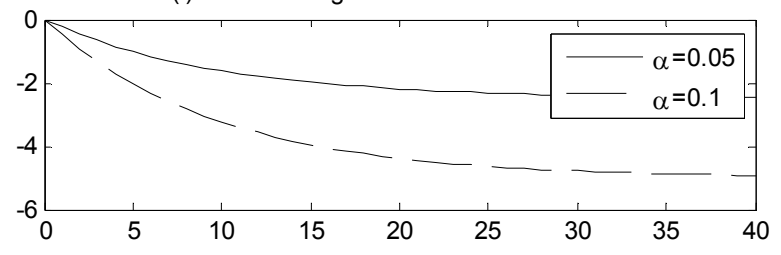

(h) Domestic employment

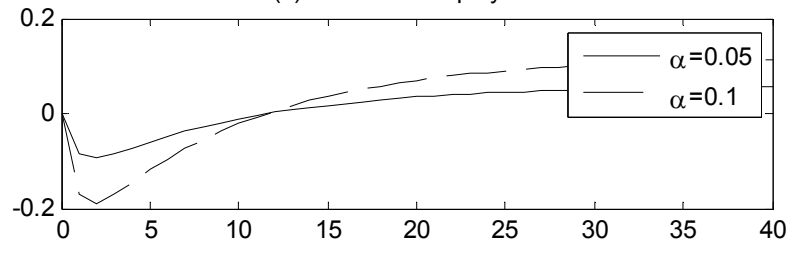

(j) Foreign welfare

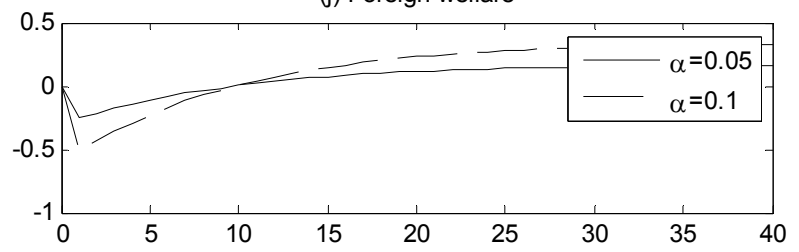

A prima facie interpretation of these results could lead to the conclusion that a domestic shift in the composition of public spending towards public infrastructure worsens the sustainability of the domestic economy by increasing its external debt. However, if we take the view that public capital increases a country's net worth (see, for example, Milesi-Ferretti and Moriyama (2006)), then the accumulation of external debt does not necessarily imply a 
worsening of total domestic net worth, since it is more than offset by the permanent increase in public capital.

Figure 1 also highlights the role of $\alpha$. A higher $\alpha$ increases the productivity of public capital more, thus implying a further expansion of production possibilities, which results in higher domestic output. An increase in $\alpha$ also increases the domestic marginal productivity of labor; this allows domestic firms to produce more output for a given labor input. Equations (18) and (24) imply that an increase in $\alpha$ would reduce prices if these were perfectly flexible. However, due to the presence of nominal rigidities, prices cannot be reduced to fully match the increase in productivity. The fact that output increases while prices are only partially adjusted results in higher domestic profits in the short run. Since domestic firms are owned by domestic households, higher profits are re-distributed to them, partly translating into higher consumption for a higher level of $\alpha$.

Figure 1(h) also shows that a shift in the composition of spending has a non-monotonic impact on home employment, since it tends to reduce it in the short run, but raise it in the medium and long run. In addition, an increase in $\alpha$ has a similar non-monotonic impact. This can be seen by comparing the results for $\alpha=0.05$ and $\alpha=0.1$ in Fig. 1 (h). A higher $\alpha$ generates lower domestic employment in the short-run (the first ten periods after the shock) but higher domestic employment afterwards.

The results described above reflect various effects at work following an increase in the level and productivity of public capital. One obvious implication of higher and/or more productive public capital is that the same level of output can be produced with less labor effort. This "pure public capital productivity" effect explains why domestic employment initially falls when the level of public capital is increased, and why it falls more if the productivity of public capital is higher.

However, higher and more productive public capital also implies that, on average, the prices of domestic goods are lower. This raises the real wage, thus generating incentives for higher domestic labor supply. In addition to this increase in the real wage, the domestic accumulation of current account deficit reduces domestic households' net wealth, thus pushing them to increase their labor supply (i.e. to decrease their consumption of leisure). In the medium and long run, the wealth effect stemming from the current account deficit, together with the impact of the higher real wage, more than offset the pure public capital productivity effect. The interaction of these various effects thus explains the non-monotonic impact of both a shift towards public capital and of a higher $\alpha$ on domestic labor supply. Intuitively, these results imply that the short-run impact of productive capital in the economy might result in a job-less expansion, due to the generalized increase in productivity, while in the medium and long run the benefits of expanding the production possibilities of the economy will manifest themselves not only on economic activity but also on employment. 


\section{B. The Open Economy Impact}

As we stressed in the Introduction, one advantage of the open economy set-up is that it enables us to assess the impact of shifts in public spending composition on the exchange rate and on foreign variables.

Figure 1(e) shows that an increase in productive capital in the domestic economy implies an appreciation of the domestic exchange rate (a fall of the price of the foreign currency expressed in terms of the domestic currency). The main mechanism at work is a "money demand" effect arising through higher domestic consumption (see also Ganelli 2005): as discussed in Section 4.1, domestic consumption increases, both in absolute terms and relative to foreign one, when the domestic government shifts its spending composition towards productive capital. Since money demand is a positive function of consumption (see equations 10 and 11), an increase in domestic consumption relative to foreign one increases domestic money demand compared to foreign one. An appreciation of the domestic currency is therefore required to reestablish equilibrium in the money market. The fact that domestic consumption increases more when $\alpha$ is higher implies that the money demand effect is stronger in that case. This explains why the domestic currency appreciates even more when public capital is more productive.

Figure 1(c) also shows that foreign output increases in the short run and slightly declines in the long run following a shift in domestic public spending composition, while foreign private consumption displays an opposite response. The short-run increase in foreign output can be explained by both an "expenditure switching" and an "expenditure boosting" effect. The expenditure switching effect is due to the fact that an appreciation of the domestic currency makes foreign goods cheaper. This shifts some of the higher world demand away from domestic and towards foreign goods. However, since the effect on the exchange rate is small in our model, so is the expenditure switching effect.

What accounts for the bulk of the short-run increase in foreign output is therefore the expenditure boosting effect, due to higher aggregate demand in the world economy in the wake of an increase in production possibilities in the domestic economy. As we have seen, an immediate implication of the latter is a consumption boom in the domestic economy. Since household preferences do not display home bias, part of the higher domestic demand falls on foreign goods, thus explaining why foreign output increases on impact. The importance of the expenditure boosting effect is amplified in our model by the fact that, due to the presence of imperfect competition, the initial output level is sub-optimally low both domestically and abroad.

The decrease in private foreign consumption in the short run can be explained with the help of the initial steady-state equations (Equations 27-30). Taking in to account that the initial endowment of natural resources of the two countries is normalized in the simulations ( $K_{0}=K_{0}^{*}=1$ ), the initial steady state equations for the domestic and foreign country, respectively, become 
$y_{0}=l_{0}=\frac{\theta-1}{\theta} \frac{1}{C_{0}}$

$y_{0}^{*}=l_{0}^{*}=\frac{\theta-1}{\theta} \frac{1}{C_{0}^{*}}$

Equations (31) and (32) are valid only for the initial steady state and under the assumption of fully flexible prices. An interpretation of these equations is therefore that - neglecting both the distortions due to price rigidities and the international impact of the shift in public spending composition in the domestic country - there should in each country be a negative relationship between the levels of output and consumption. The intuition for such negative relationship is found in the need to keep households' supply of labor on an optimal path according to equations (8) and (9). Abstracting from fiscal policy shocks, the private utility function (1) and the production function (16) (and their foreign counterparts) imply that if output increases the marginal disutility of providing an additional amount of labor also increases. In order to keep the latter disutility equal to the marginal utility of private consumption that the increase in labor supply can buy, the marginal utility of private consumption must also increase, and this can only be achieved with a lower level of private consumption.

As we have already stressed above, equations (31) and (32) do not bind after the initial steady state is disturbed. However, the fact that government spending composition is unchanged in the foreign country ( $G^{I^{*}}=0$ at every horizon) implies that the relationship between domestic output and domestic consumption is likely to bear some resemblance to the one described by equation (32) in the periods immediately after the initial shock. Equation (32) is more likely to be relevant than equation (31) in these periods because the increase in domestic productive public capital after the shock $\left(K^{G}>0\right)$ allows higher output with the same (or lower) level of labor input and therefore breaks the inverse relationship between output and private consumption that we discussed above. This makes it easier in the domestic economy, compared to the foreign one, to have at the same time higher output and higher private consumption.

Our interpretation is also consistent with the fact that in the long run the relationship between foreign output and foreign private consumption becomes more difficult to explain with reference to equation (32). Intuitively, the mechanism summarized by (32) is more likely to be relevant the smaller is the deviation from the initial steady state. In the long run, the accumulation of external assets by foreign households - the other side of the coin of the current account deficit run by the domestic country-implies an increase in both private consumption and leisure of foreign residents.

In addition, a "terms-of-trade" effect is at work in the long run. A rise in supply of domestic goods worsens the domestic terms of trade (i.e. the price of domestic goods relative to foreign falls). This implies that foreign consumption is higher in the long run. Both the accumulation of external assets and the worsening in the domestic terms of trade have a positive effect on long-run foreign private consumption. 


\section{Welfare Impact}

In this Section we focus on changes in momentary utility. The change in domestic utility in period $t$ is given by

$$
\Delta U_{t}=\hat{C}_{t}-l_{0}^{2} \hat{l}_{t}+\phi \hat{G}_{t}^{C}
$$

while an analogous expression holds for foreign utility. ${ }^{8}$

As we stressed in the Introduction, the trade-off between utility-enhancing public consumption and productivity-enhancing public capital is often a crucial aspect of the public debate and of policy discussions. In spite of this, we are not aware of any paper which explicitly focuses on this trade-off in the NOEM framework. The basic intuition behind this trade-off is that cutting spending for public consumption directly reduces households utility. However, if the cut in current spending is used to raise public capital, this shift can also have a positive indirect effect on households utility, namely through the impact of improved public infrastructure on other variables which affect private utility.

\section{Domestic Welfare}

Figure 1(i) illustrates the response of domestic momentary utility to changes in government spending composition for various combinations of the productivity of public capital $(\alpha)$ and the weight of public consumption in private utility $(\phi)$. Figure 1(i) shows that a shift in composition toward public capital is more likely to be welfare enhancing in every period for domestic households the higher is $\alpha$ and the lower $\phi$. The intuition behind these results is straightforward. Since a decrease in public consumption directly lowers welfare, the direct utility loss of a shift in the composition of spending is lower if households attach a low weight to public consumption in their utility function. In addition, the loss due to lower public consumption can be compensated by the fact that higher public infrastructure allow households to consume more privately at every horizon. Furthermore, this effect is stronger for higher values of $\alpha$ (Figure 1(b)). This effect is reinforced also because higher consumption can be achieved domestically without having to increase labor proportionally to the increase in consumption. On the contrary, labor effort can even be reduced in the short term (Figure 1(h)).

Overall, the results presented in Figure 1(i) suggest that a shift toward public infrastructure is likely to be welfare enhancing domestically, unless the weight of public consumption (compared to private consumption) in private utility is high and/or the productivity of public capital is low. However, since a negative welfare impact cannot be ruled out, the results also imply that governments should take into account household preferences with respect to public provision of services in order to evaluate shifts in the composition of public spending.

\footnotetext{
${ }^{8}$ As customary in this literature, we neglect the utility derived from real balances.
} 
Similarly, given the importance of changes in $\alpha$ for the welfare results, the impact of planned infrastructure projects on the productivity of the private sector should be evaluated as carefully as possible before changing the public spending mix.

\section{Foreign Welfare}

Figure 1(j) presents the impact on foreign households' welfare of a domestic shift in public spending composition. The foreign equivalent of the production function (16), the assumption that the country's endowment of natural resources is normalized to 1 , and the absence of a shift in foreign public spending composition imply that foreign output is equal to foreign employment at any time. In other words, foreign households do not benefit from the expansion of production possibilities experienced in the home country which allows domestic residents to consume more without necessarily increasing their work effort. As we have seen in Section 4.2, foreign private consumption falls and foreign employment increases in the short run following the domestic policy shock. The international consequence of the shift in public spending decided by the home country is therefore a reduction of foreign welfare in the short run. This negative international welfare spillover is reversed in the medium and long run, due to the changes in the paths of foreign private consumption and employment discussed in section 4.2.

Figure 1(j) also shows that the negative short-run impact on foreign welfare is stronger for higher values of $\alpha$. This has interesting implications for international policy coordination. In the short run, the more efficient is the reallocation of public spending decided by the domestic authorities (the higher $\alpha$ ), the more the domestic policy change harms foreign residents. The intuitive explanation for this result is that having more efficient infrastructure generates a competitive advantage for the domestic economy compared to the foreign. The domestic expansion of productive possibilities also generates some positive international demand spillovers which partially benefit foreign residents. However, foreign residents have to meet the increased global demand within a relatively underdeveloped (compared to domestic) public infrastructure system. This implies that the positive spillover impact of the domestic policy shift is not enough to offset the domestic competitive advantage the shift generates and therefore does not prevent foreign welfare from falling in the short run.

One implication of this analysis is that the domestic policy change can generate incentives for reallocation of public spending also in the foreign country. In order to avoid short-run welfare losses, it is in the best interest of the foreign country to also increase the level of its productive public capital in response to the domestic policy. A domestic policy shift can therefore trigger a virtuous global technological cycle. 


\section{A Temporary Shift in Government SPENDing Composition}

In this Section we assess the impact of a temporary shift in domestic government spending composition. In this policy experiment the persistency parameter $\rho$ is set to 0.8 in equations (14) and (15). Figure 2 illustrates the results in this case. ${ }^{9}$

After about 40 periods following the shock, depreciation of public capital implies that the stock of public infrastructure accumulated while public investment was temporary higher is almost completely depleted. This dynamics implies that the increase in productivity of domestic firms is also only temporary. The temporary increase in productivity brings about a temporary rise in domestic output, which is, for obvious reasons, more pronounced for higher values of $\alpha$ (Figure 2(a)). Domestic households also temporary increase consumption following the temporary increase in productivity (Figure 2(b)). For consumption smoothing reasons analogous to those discussed in Section 4.1, domestic households save part of the temporary higher income by running a current account surplus in the medium run. Figure 2(f) shows that domestic residents accumulate a permanently higher amount of bonds. One of the implications of a temporary increase in the stock of public infrastructure is therefore a permanent improvement in the net worth position of the domestic economy. Due to higher interest income, domestic private consumption is higher in the new steady state.

The short-run response of foreign output and consumption is similar to the one displayed in the case of permanent shifts in government spending composition, and can be explained with arguments analogous to the ones discussed in Section 4.2. However, since the total expenditure boosting effect stemming from an increase in domestic productivity is smaller over the time horizon considered, the reaction of foreign variables is also quantitatively more limited in the case of temporary shifts.

The accumulation of a current account deficit implies that foreign residents reduce both their private consumption and their leisure (increase output) in the long run, due to reduced wealth. However, they intertemporally smooth this behavior, thus temporarily increasing their leisure and consumption in the medium term (Figure 2(c,d)). In addition, the more pronounced medium-run fall in foreign output in the case of a higher $\alpha$ can also reflect some market gains of domestic firms at the expense of foreign firms, since the nominal appreciation of the domestic currency (Figure 2(e)) is more than offset by the fact that domestic prices are likely to fall more than foreign prices in the medium run when $\alpha$ is higher. This in turn is because a higher level of $\alpha$ reduces domestic (but not foreign) marginal costs and therefore domestic (but not foreign) prices.

\footnotetext{
9 Figures 2 shows that, although the solution of the model is stable, it takes more than 40 periods to reach the new steady state.
} 
Figure 2. The Effects of a Temporary Shift in Government Spending Composition

(a) Domestic output

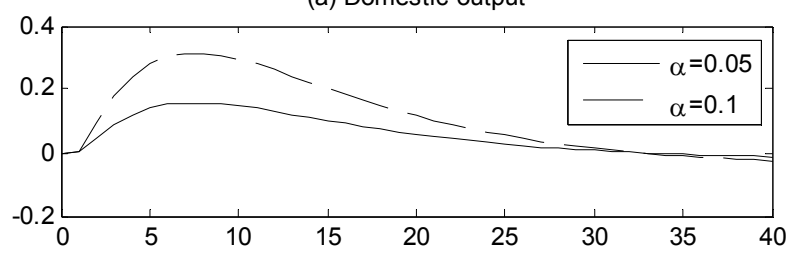

(c) Foreign output

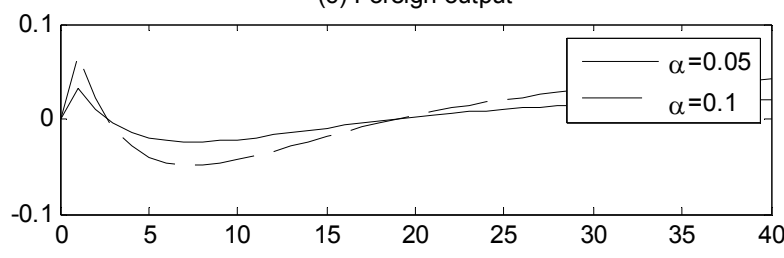

(e) Nominal exchange rate

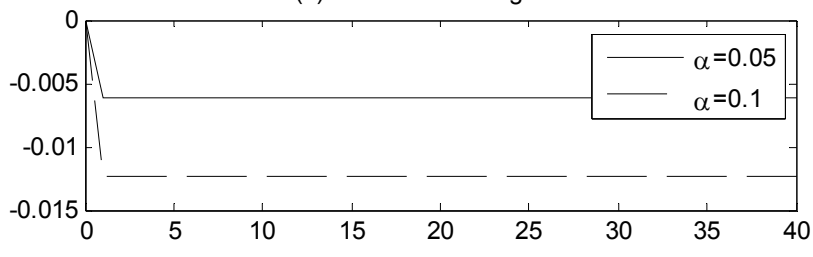

(g) Domestic public capital

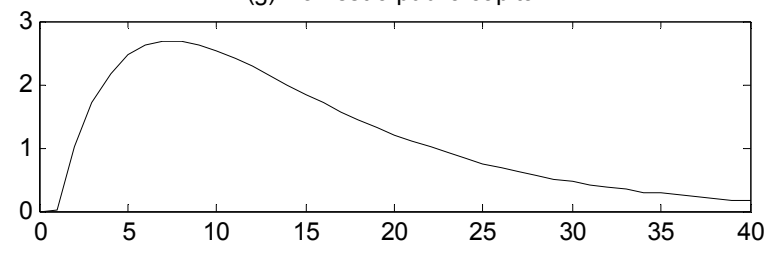

(i) Domestic welfare

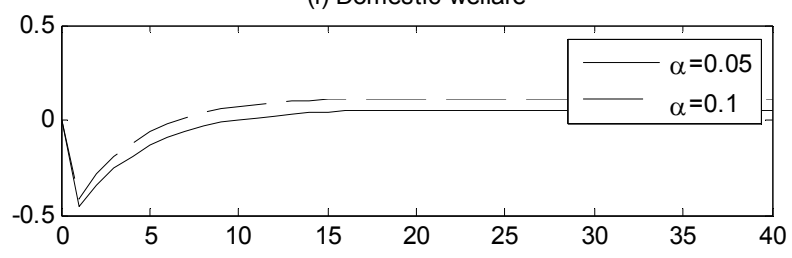

(b) Domestic private consumption

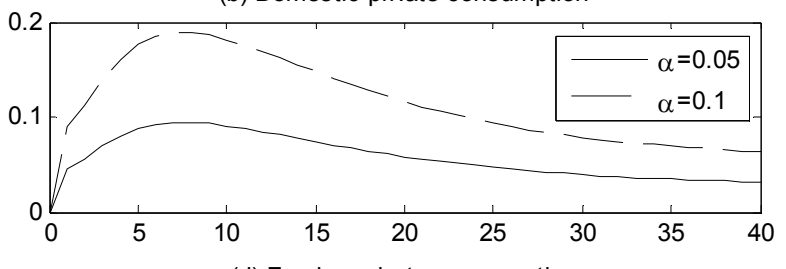

(d) Foreign private consumption
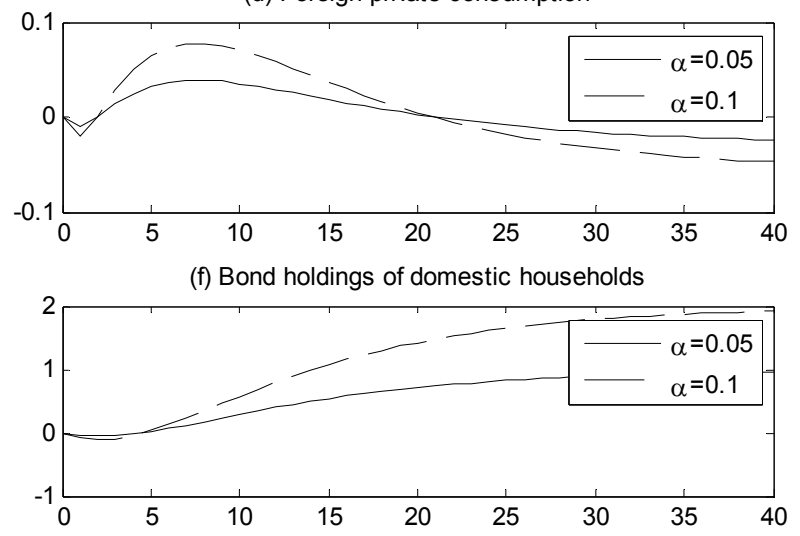

(h) Domestic government spending
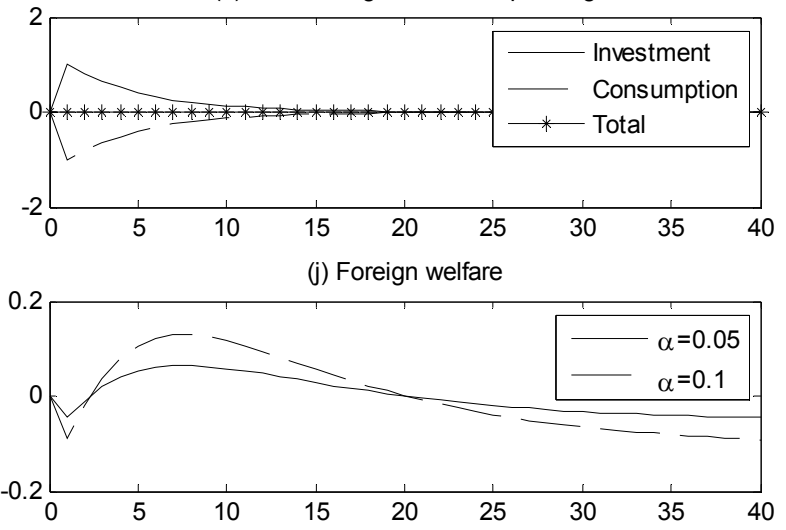

Figure 2(i) shows that, contrary to the case of a permanent shift, a temporary domestic policy shift can reduce domestic welfare in the short run even when $\alpha$ is high (i.e. $\alpha=0.1$ ). This can intuitively be explained by the fact that the expansion of production possibilities is much more limited when the shift is only temporary. Domestic households therefore cannot expand private consumption as much as in the permanent case. The impact of the reduction of public consumption hence dominates domestic utility in the short run. In the long run, $G_{t}^{C}$ returns to the initial level, thus neutralizing the negative welfare impact of the temporary reduction in public consumption. However, domestic welfare increases in the long run (rather than just returning to the pre-shock level) because the higher wealth accumulated by domestic residents through running a current account surplus allows them to reduce their supply of labor while at the same time increasing private consumption. 
The impact on foreign welfare is driven by foreign consumption and output movements, and is negative in the short and the long run but briefly positive in the medium run. Overall, the welfare loss of foreign agents is more limited compared to domestic residents, because foreigners do not see their utility reduced by a cut in publicly provided consumption.

The results presented in Figure 2 imply that a temporary shift of spending composition towards public infrastructure is likely to be harmful for domestic welfare. One obvious policy implication is that governments which value the welfare of their citizens should ensure, before embarking on large public infrastructure projects, that the fiscal resources necessary to maintain the increased capital stock can be secured in the medium and long run. Otherwise, the temporary increase in domestic productivity might not be enough to compensate for the utility loss due to lower public consumption.

\section{Conclusions}

In this paper we focused, in the context of an open-economy model with imperfect competition and nominal rigidities, on the trade-offs faced by governments in deciding the allocation of public spending between productivity-enhancing public infrastructures and utility-enhancing public consumption in an open economy.

Our analysis shows that shifts in the composition of public spending have important positive and welfare implications, both domestically and abroad. In particular, a temporary increase in the domestic stock of public capital financed by a reduction in public consumption is likely to reduce domestic welfare because the temporary gains from higher productivity do not fully compensate domestic residents for the utility loss due to lower public consumption. If the policy shift is permanent, domestic utility is likely to increase, provided that the productivity of government spending is not too low and the importance of government spending (relative to private consumption) in private utility is not too high. On the other hand, foreign residents can suffer substantial short-run welfare losses. This implies that the domestic reallocation of public spending might generate incentives for the foreign country to also increase its level of productive capital in order to avoid welfare losses, thus resulting in a virtuous global technological cycle.

Of course, some of our results might be sensitive to the particular modeling strategy and assumptions adopted in this paper. Further research could investigate the robustness of the results presented here. An interesting extension of the model would be the introduction of private capital in the production function of private firms. An analysis of the implications of asymmetry between the domestic and foreign countries (for example by introducing home bias in private and public consumption) would also be of interest. 


\section{REFERENCES}

Alesina, Alberto, and Roberto Perotti, 1995, "Fiscal Expansions and Adjustments in OECD Countries," Economic Policy 10, pp. 205-48.

Aschauer, David A., 1989, “Is Public Expenditure Productive?” Journal of Monetary Economics 23, pp. 177-200.

Barro, Robert J., 1990, “Government Spending in a Simple Model of Endogenous Growth," Journal of Political Economy 98, pp. 103-125.

Barro, Robert J. and Xavier Sala-I-Martin, 1992, "Public Finance in Models of Economic Growth," Review of Economic Studies 59, pp. 645-661.

Baxter, Marianne, and Robert K. King, 1993, "Fiscal Policy and General Equilibrium," American Economic Review 83, pp. 315-334.

Benigno, Gianluca, and Pierpaolo Benigno, 2003, "Price Stability in Open Economy," Review of Economic Studies 70, pp. 743-764.

Bergin, Paul, 2003, "Putting the New Open Economy Macroeconomics to a Test," Journal of International Economics 60, pp. 3-34.

Betts, Caroline, and Michael B. Devereux, 2000, "Exchange Rate Dynamics in a Model of Pricing-to-Market," Journal of International Economics 50, pp. 215-244.

Betts, Caroline, and Michael B. Devereux, 2001, "The International Effects of Monetary and Fiscal Policy in a Two-Country Model," in Money, Capital Mobility and Trade: Essays in Honor of Robert Mundell, Calvo, G., Dornbusch, R. and Obstfeld, M. (eds.). MIT Press, Cambridge.

Calvo, Guillermo A., 1983, "Staggered Prices in a Utility Maximizing Framework," Journal of Monetary Economics 12, pp. 383-398.

Corsetti, Giancarlo, and Paolo Pesenti, 2001, "Welfare and Macroeconomic Interdependence," Quarterly Journal of Economics 116, pp. 421-446.

Coto-Martinez, Javier, 2006, "Public Capital and Imperfect Competition," Journal of Public Economics 90, pp. 349-378.

Coutinho, Leonor, 2005, "Fiscal Policy in the New Open Economy Macroeconomics and Prospect for Fiscal Policy Coordination," Journal of Economic Surveys 19, pp. 789822. 
Devereux, Michael B., and Charles Engel, 2002, "Exchange Rate Pass-Through, Exchange Rate Volatility, and Exchange Rate Disconnect," Journal of Monetary Economics 49, pp. 913-940.

Duggal, Vijaya G., Saltzman, Cynthia, and Lawrence R. Klein, 2007, "Infrastructure and Productivity: an Extension to Private Infrastructure and Its Productivity," Forthcoming in Journal of Econometrics.

Feltenstein, Andrew, and Stephen Morris, 1990, "Fiscal Stabilization and Exchange Rate Instability: a Theoretical Approach and Some Policy Conclusions Using Mexican Data," Journal of Public Economics 42, pp. 329-356.

Finn, Mary, 1998, "Cyclical Effects of Government Employment and Goods Purchases," International Economic Review 39, pp. 635-657.

Ganelli, Giovanni, 2005, "The New Open Economy Macroeconomics of Government Debt," Journal of International Economics 65, pp. 167-184.

Ghironi, Fabio, 2006, "Macroeconomic Interdependence under Incomplete Markets," Journal of International Economics, pp. 76, 428-450.

Glomm, Gerard. and B. Ravikumar, 1997, "Productive Government Spending and Long-Run Growth”, Journal of Economic Dynamics and Control 21, pp. 183-204.

Gramlich, Edward, M., 1994, "Infrastucture Investment: a Review Essay,” Journal of Economic Literature 32, pp. 1176-96.

Hau, Harald, 2000, "Exchange Rate Determination: the Role of Factor Price Rigidities and Nontradables," Journal of International Economics 50, pp. 421-447.

Hulten, Charles R., and Robert .M. Schwab, 1991, "Public Capital Formation and the Growth of Regional Manufacturing Industries”, National Tax Journal, pp. 121-134.

Kalaitzidakis, Pantelis, and Sarantis Kalyvitis, 2004, "On the Macroeconomic Implications of Maintenance in Public Capital," Journal of Public Economics 88, pp. 695-712.

Klein, Paul, 2000, "Using the Generalized Schur Form to Solve a Multivariate Linear Rational Expectations Model," Journal of Economic Dynamics and Control 24, pp. 1405-1423.

Kollmann, Robert, 2002, "Monetary Policy Rules in the Open Economy: Effects on Welfare and Business Cycles," Journal of Monetary Economics 49, pp. 989-1015.

Lane, Philip R., 2001, “The New Open Economy Macroeconomics: a Survey,” Journal of International Economics 54, pp. 235-266. 
Lane, Philip R., and Giovanni Ganelli, 2003, "Dynamic General Equilibrium Analysis: The Open Economy Dimension," Published in Elements in Dynamic Macroeconomic Analysis (S. Altug, J. Chadha, C. Nolan, eds), Cambridge University Press.

Lane, Philip .R., and Roberto Perotti, 2003, “The importance of Composition of Fiscal Policy: Evidence from Different Exchange Rate Regimes," Journal of Public Economics 87, pp. 2253-79

Linnemann, Ludger, and Andreas Schabert, A, 2006, "Productive Government Expenditure in Monetary Business Cycle Models," Scottish Journal of Political Economy 53, pp. $28-46$.

McCallum, Bennett, 2001, Software for RE Analysis. Computer software available at http://wpweb2.tepper.cmu.edu/faculty/mccallum/research.html

Milesi-Ferretti, Gian Maria, and Kenji Moriyama, 2006, "Fiscal Adjustment in EU Countries: a Balance Sheet Approach," Journal of Banking and Finance 30, pp. 3281-98, also published as IMF Working Paper 04/143.

Obstfeld, Maurice, and Kenneth Rogoff, 1995, “Exchange Rate Dynamics Redux,” Journal of Political Economy 103, pp. 624-660.

Obstfeld, Maurice, and Kenneth Rogoff, 1996, Foundations of International Macroeconomics. MIT Press, Cambridge.

Obstfeld, Maurice, and Kenneth Rogoff, 2000, "New Directions for Stochastic Open Economy Models," Journal of International Economics 50, pp. 117-153.

Obstfeld, Maurice, and Kenneth Rogoff, 2002, “Global Implications of Self-Oriented National Monetary Rules,” Quarterly Journal of Economics 117, pp. 503-36.

Pierdzioch, Christian, 2004, "Capital Mobility and the Effectiveness of Fiscal Policy in Open Economies," Journal of Macroeconomics 26, pp. 465-79.

Rioja, Felix K., 1999, "Productiveness and Welfare Implications of Public Infrastructure: a Dynamic Two-Sector General Equilibrium Analysis," Journal of Development Economics 58, pp. 387-404.

Rioja, Felix K., 2003, "Filling Potholes: Macroeconomic Effects of Maintenance Versus New Investments in Public Infrastructure," Journal of Public Economics 87, pp. 2281-2304

Roche, Maurice J., 1996, "Government Spending and the International Business Cycle," Canadian Journal of Economics 29, pp. 865-884. 
Sarno, Lucio, 2001, "Toward a New Paradigm in Open Economy Modeling: Where Do We Stand?," Federal Reserve Bank of St. Louis Review 83, pp. 21-36.

Smith, Adam, 1776, An Inquiry into the Nature and Causes of the Wealth of Nations.

Sutherland, Alan, 1996, "Financial Market Integration and Macroeconomic Volatility," Scandinavian Journal of Economics 98, pp. 521-539.

Sutherland, Alan, 2005, "Incomplete Pass-Through and the Welfare Effects of Exchange Rate Variability,” Journal of International Economics 65, pp. 375-400.

Tervala, Juha 2006, "Productive Government Spending and the International Transmission of Fiscal Policy,” HECER Discussion Paper 120.

Tille, Cedric, 2001, "The Role of Consumption Substitutability in the International Transmission of Shocks," Journal of International Economics 53, pp. 421-444.

Turnovsky, Stephen J., and Walter H. Fisher, 1995, "The Composition of Government Expenditure and Its Consequences for Macroeconomic Performance," Journal of Economic Dynamics and Control 19, pp. 747-786. 